\title{
Prevalence of hypertension and associated risk factors among university students: Comparative study
}

\author{
Maha Moussa Mohamed Moussa , Reda Ibrahim El-mowafy, Hanan Hassan El-Ezaby \\ Department of Community Health Nursing, Faculty of Nursing, Port-Said University, Port-Said City, Egypt
}

Received: June 29, 2015

Accepted: December 7, 2015 Online Published: January 4, 2016

DOI: $10.5430 /$ jnep.v6n5p19

URL: http://dx.doi.org/10.5430/jnep.v6n5p19

\begin{abstract}
Background: Hypertension is commonly known as the "silent killer", its prevalence is highly variable worldwide and it's an important risk factor for cardiovascular disease. The increase of hypertension in the developing countries may be connected with the economic transition within those countries. This study aimed to assess the prevalence of hypertension among university students and the associated risk factors related to hypertension.

Methods: The study used a comparative cross-sectional design. Data were collected from October 2013 to May 2014 at the student University Hostels in Port-Said and Damietta Cities. The sample included 2,029 university students. The data were collected by a structured interview questionnaire, which included data about nutritional lifestyle, stress, exercises, family history and smoking pattern. In addition, blood pressure and body mass index were measured.

Results: The prevalence of hypertension was $26.5 \%$ among students in Damietta University compared to $18.1 \%$ of students in Port-Said University. The Univariate analysis showed an association between hypertension and age, sex, body mass index (BMI), nutritional lifestyle, stress, physical activity, family history and smoking pattern $(p<.05)$. Multivariate logistic regression analysis revealed a significant association between hypertension and the above stated factors.

Conclusions and recommendations: The findings of the present study highlighted the prevalence of hypertension among students in Damietta University (26.5\%), compared to $18.1 \%$ among students in Port Said university. The blood pressure values increased with associated risk factors (age, sex, body mass index, smoking, strss, physical activity and family history). The results of this study recommended that periodic screening and monitoring of students for hypertension should be incorporated into the entrance of the university physical examination, and university students health education on hypertension as a disease and its associated risk factors should be strengthened.
\end{abstract}

Key Words: Hypertension, Risk factor, Students university, Hostel

\section{INTRODUCTION}

Hypertension is the commonest non communicable disease affecting both sexes in all races. ${ }^{[1]}$ It is the most prevalent cardiovascular disease risk factor worldwide. National Hypertension of the Egyptian survey of adults conducted in six Egyptian governorates, and had been estimated the prevalence of hypertension as $26.3 \%$. ${ }^{[2]}$
Hypertension is classified into two group's primary hypertension of unknown cause and secondary hypertension caused by several affected organs. ${ }^{[3]}$ The Seventh Report of the Joint National Committee on the Prevention Detection, Evaluation, and Treatment of High Blood Pressure (JNC7) introduced a new hypertension category "pre-hypertension", defined as a systolic blood Pressure of 120 to $139 \mathrm{mmHg}$ and/or a dias-

\footnotetext{
*Correspondence: Maha Moussa Mohamed Moussa; Email: mahamoussa10@yahoo.com; Address: Department of Community Health Nursing, Faculty of Nursing, Port-Said University, Arab District, Oraby and El-Etehad street, Port-Said City, Egypt.
} 
tolic blood pressure of 80 to $89 \mathrm{mmHg} .{ }^{4]}$ Pre-hypertension individuals have a greater risk of developing hypertension than those with lower blood pressure levels. ${ }^{[5]}$

Adolescents have a high and increasing burden of hypertension and related disease, with cardiovascular diseases among the leading causes of death. ${ }^{[6]}$ Several studies have shown that hypertension and pre-hypertension can start in adolescence, perhaps in the early stages of life, and continue into adulthood. ${ }^{[7,8]}$

Several risk factors are well-recognized worldwide as contributors to the increase in blood pressure. They include smoking habit, family history of hypertension and increased glycemic and lipid levels. ${ }^{[9,10]}$ However, the majority of the risk factors like tobacco use, unhealthy diet, physical inactivity, overweight and obesity can be effectively prevented. ${ }^{[6]}$

Community health nurses play an important role in promoting youth health. Traditionally, the focus of health promotion by nurses has been on disease prevention and changing the behavior of individuals with respect to their health. Nurses' strategies for health promotion included giving information to young students and providing health education. ${ }^{[11]}$

Most of the studies done in Egypt examined the prevalence of hypertension in adults. Hence, little is known about the prevalence of hypertension among University students. In addition, it is well-known that hypertension is an asymptomatic disease that is revealed only when there are complications. So, it is very important to identify the population at risk through early identification at an early age. The present study was conducted to determine the prevalence of hypertension among university students. In addition, the study identified the associated risk factors related to hypertension.

\section{Aim of the study}

This study aimed to assess the prevalence of hypertension among university students and the associated risk factors related to hypertension.

\section{MeTHODS}

\subsection{Design}

The study was conducted using a comparative cross-sectional study design.

\subsection{Setting}

The study was carried out in Port-Said and Damietta University Hostels.

\subsection{Sample size}

The study constituted 2,029 students, from Port-Said University were 895 (339 males and 556 females) and from Dami- etta University were 1,134 (394 males and 740 females). Students were selected using systematic sampling technique: from each university hostel were chosen randomly using students list of the hostel (if one of the students were absent, the following student on the list was chosen, to constitute the study sample). However, eligibility criteria included students who were aged 18 to 25 years old; living in the hostels and willing to participate in the study. Students who had chronic illnesses such as diabetes, renal disease or pregnant students were excluded from the study.

\subsection{Data collection}

The data were collected using the following tools:

\subsubsection{Structured interview questionnaire}

A structured interview questionnaire sheet was designed by the researchers to meet the aims of the study, based on the literature review and was written in simple Arabic language to suit the students' level of understanding. SocioDemographics characteristics were collected as age, gender, marital status, residence education degree, health behaviors smoking status, physical activity, and nutritional lifestyle and family history.

\subsubsection{Physical measurements}

(1) Blood pressure (BP) measurement: BP was measured according to American Heart Association guidelines using a mercury column sphygmomanometer and a cuff suitable to the participants arm circumference. Measurements of arterial blood pressure were performed by the researcher in a quiet room after the students had rested for five minutes in a sitting position. Their right arms were kept at the same level of their heart during the measurement. BP was measured from the right upper arm with a mercury sphygmomanometer and appropriate size of cuff, and standard measures were taken to ensure accuracy. The systolic blood pressure was recorded at the appearance of relevant sounds (first Korotkoff sounds); while the diastolic blood pressure was recorded at the disappearance relevant sounds (fifth Korotkoff sounds). ${ }^{[12]}$ Three consecutive measurements were taken at an interval of at least five minutes, but only the second and third measurements were used in calculating the mean systolic and diastolic blood pressures that serve as the blood pressure of the subject. Hypertension was defined and classified according to the WHO/ISH guidelines ${ }^{[13]}$ (see Table 1).

(2) Body mass index (BMI) measurements: BMI was categorized according to the World Health Organization criteria, where a BMI of $<25 \mathrm{~kg} / \mathrm{m}^{2}$ is considered normal, a BMI between 25 and $29 \mathrm{~kg} / \mathrm{m}^{2}$ is considered overweight, and a BMI $\geq 30 \mathrm{~kg} / \mathrm{m}^{2}$ is considered obese. ${ }^{[14]}$ Weight and height were measured and BMI was calculated as weight in kilograms 
divided by height in meters squared. Every student was weighed using an electronic standardized weight scale. The student was weighed without outdoor garments and shoes. Height was measured to the nearest $0.1 \mathrm{~cm}$. All measurements were taken using a non-stretch measuring tape. Shoes were removed and height was recorded to the nearest $\mathrm{cm}$.

\subsection{Validity}

The study tools were tested for validity by five experts: two from the community medicine and three from community health nursing departments.

\subsection{Pilot study}

A pilot study was conducted on $10 \%$ of the total study sample. Its aim was to test the suitability of the questionnaire to be used regarding its phrasing, the culture of interviewees, estimated time of completing the questionnaire, testing the analytic procedure and the overall response of the students. This study revealed that the questionnaire was on the whole suitable. Those who participated in the pilot study were excluded from the main study sample.

\subsection{Filed work}

The data were collected during the period from the 1st October 2013 and to the end of May 2014. The researcher arranged with the director of hostel for the proper available days for data collection in which all students were available in the hostel, the researcher started to collect data two times per week. Data were collected using a self-constructed face-to-face interviewed questionnaire: each student took 20-30 minutes to complete the tool and to perform physical measurements at the manner of privacy in the presence of researchers.

Table 1. Classification of blood pressure

\begin{tabular}{lll}
\hline Classification & Systolic BP $\mathbf{~ m m H g}$ & Diastolic BP $\mathbf{~ m m H g}$ \\
\hline Normal & $<120$ & $<80$ \\
Pre Hypertension & $120-139$ & $80-89$ \\
Stage I Hypertension & $140-159$ & $90-99$ \\
Stage II Hypertension & $>160$ & $>100$ \\
\hline
\end{tabular}

\subsection{Ethical consideration}

Ethical issues including anonymity, confidentiality and voluntary participation were considered before starting data collection. The researchers fulfilled the official steps required to get the approval for carrying out the study. An official letter explaining the aim of the study was directed from the Dean of Faculty of Nursing in Port-Said University to the directors of the Students' University Hostels (males and females) of Port-Said and Damietta. The aims of the study and physical measurement were explained to each students to be familiar of his/her participation. It was the participants' right to reject participation or withdraw from the study at any time. This was guaranteed by no disciplinary action against them in the future.

\subsection{Statistical analysis}

Data obtained were analyzed using the Statistical Package for the Social Sciences (SPSS, version 18.0). Descriptive statistics included frequency, percentage, meanc and Standard Deviation (SD). The Chi-square and student $t$-test were performed to determine whether the rate of those with hypertensive between genders was statistically significant. Univariate analysis and multivariate logistic regression were carried out to find out associations between age, sex, BMI, nutritional lifestyle, stress, physical activity, smoking pattern and hypertension. The level of significance was adjusted at .05 .

\section{Results}

Table 2 shows the demographic characteristics of the studied sample. It was found that the study sample age ranged between 18 to more than 24 years with a mean of $(20.4 \pm 1.15$ and $20.3 \pm 1.17$ ) respectively in Damietta and Port-CSaid. About two thirds $(65.3 \% \& 62.1 \%)$ of the study sample are females and mostly single $(90.6 \%$ \& $87.7 \%)$ respectively in Damietta and Port-Said. As regards academic years, this table also demonstrates that $38.3 \%$ of the study sample in Damietta are at second degree and slightly more than Port Said. Also the table revealed that $77.7 \%$ of students are living in urban Damietta, while more than half (58.0\%) are living in rural Port-Said, and the monthly income ranged between $\leq 600$ to $\geq 3,000$ L.E.

Table 3 reveals a statistically significant differences regarding nutrition, drinks, stress, smoking and physical activity among university students in Damietta and Port-Said.

Table 4 demonstrates a statistically significant differences between systolic blood pressure and diastolic blood pressure with student sex (male and female) regarding Damietta and Port-Said University. As well as there is statistically significant differences between BMI with students (male and female) regarding Damietta and Port Said Universities at $p<$ .001 . 
Table 2. Demographic characteristics of studied sample groups

\begin{tabular}{|c|c|c|c|c|c|c|}
\hline & \multicolumn{2}{|c|}{ Damietta $(n=1,134)$} & \multicolumn{2}{|c|}{ Port said $(n=895)$} & \multirow{2}{*}{$\chi^{2}$} & \multirow{2}{*}{$p$} \\
\hline & No. & $\%$ & No. & $\%$ & & \\
\hline \multicolumn{7}{|l|}{ Age(years) } \\
\hline $18-20$ & 256 & 22.6 & 224 & 25.0 & \multirow{4}{*}{3.894} & \multirow{4}{*}{.273} \\
\hline $20-22$ & 682 & 60.1 & 542 & 60.6 & & \\
\hline $22-24$ & 176 & 15.5 & 115 & 12.8 & & \\
\hline$>24$ & 20 & 1.8 & 14 & 1.6 & & \\
\hline Mean \pm SD & \multicolumn{2}{|c|}{$20.4 \pm 1.15$} & \multicolumn{2}{|c|}{$20.3 \pm 1.17$} & \multicolumn{2}{|l|}{$.009^{*}$} \\
\hline \multicolumn{7}{|l|}{ Gender } \\
\hline Male & 394 & 34.7 & 339 & 37.9 & \multirow{2}{*}{2.128} & \multirow{2}{*}{.145} \\
\hline Female & 740 & 65.3 & 556 & 62.1 & & \\
\hline \multicolumn{7}{|l|}{ Marital status } \\
\hline Single & 995 & 87.7 & 810 & 90.6 & \multirow{2}{*}{$4.182^{*}$} & \multirow{2}{*}{$.041^{*}$} \\
\hline Married & 139 & 12.3 & 84 & 9.4 & & \\
\hline \multicolumn{7}{|c|}{ Academic years } \\
\hline 1 & 292 & 25.7 & 315 & 35.2 & \multirow{4}{*}{$95.777^{*}$} & \multirow{4}{*}{$<.001^{*}$} \\
\hline 2 & 434 & 38.3 & 338 & 37.8 & & \\
\hline 3 & 88 & 7.8 & 131 & 14.6 & & \\
\hline 4 & 320 & 28.2 & 111 & 12.4 & & \\
\hline \multicolumn{7}{|l|}{ Residence } \\
\hline Urban & 881 & 77.7 & 376 & 42.0 & \multirow{2}{*}{$270.132^{*}$} & \multirow{2}{*}{$<.001 *$} \\
\hline Rural & 253 & 22.3 & 519 & 58.0 & & \\
\hline \multicolumn{7}{|c|}{ Income(Egypt. pounds) } \\
\hline$\leq 600$ & 97 & 8.6 & 230 & 25.7 & \multirow{6}{*}{$187.609^{*}$} & \multirow{6}{*}{$<.001^{*}$} \\
\hline $601-800$ & 535 & 47.2 & 420 & 46.9 & & \\
\hline $801-1,000$ & 355 & 31.3 & 138 & 15.4 & & \\
\hline $1,001-2,000$ & 103 & 9.1 & 43 & 4.8 & & \\
\hline $2,000-3,000$ & 25 & 2.2 & 9 & 1.0 & & \\
\hline$\geq 3,000$ & 19 & 1.7 & 55 & 6.1 & & \\
\hline
\end{tabular}

Table 3. Distribution of the study sample groups regarding their risk factors

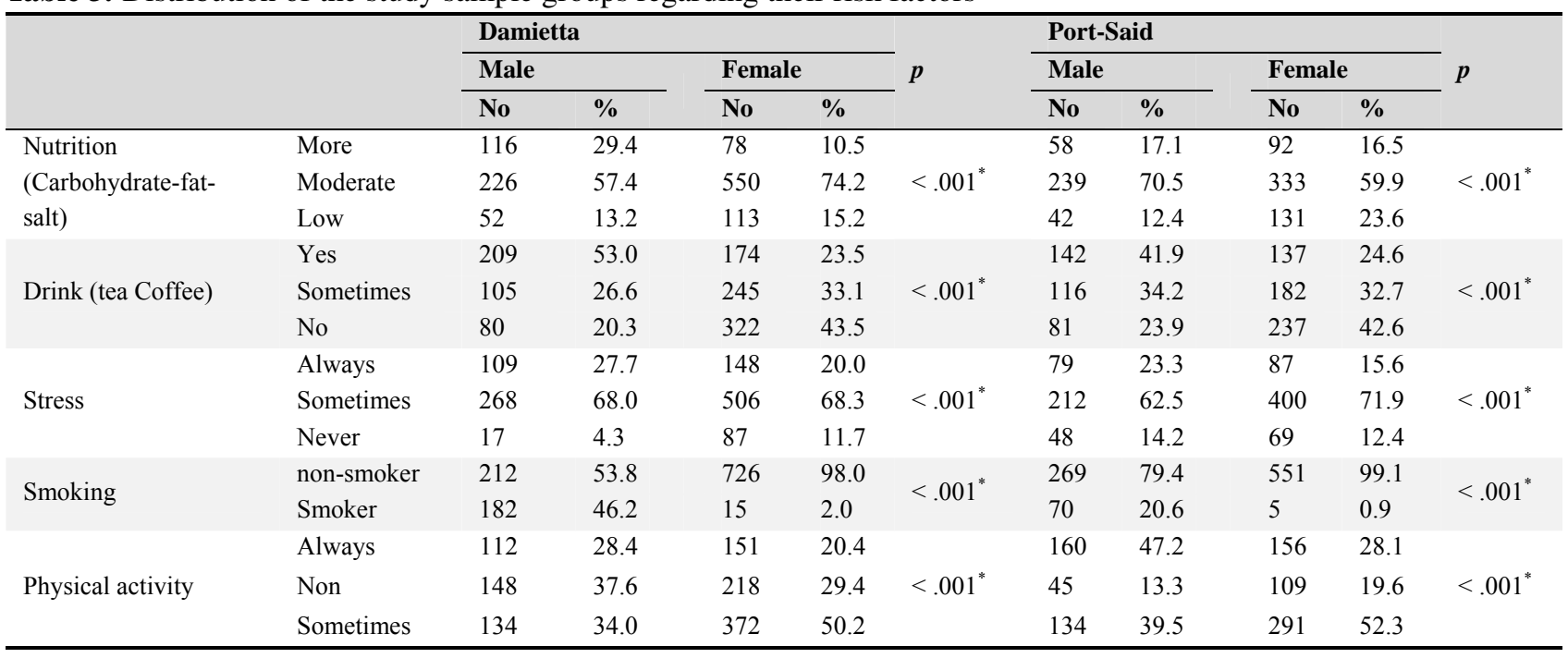

*: Statistically significant at $p \leq .05$.

Table 5 reveals the prevalence of hypertension was $26.5 \%$ among students in Damietta University, and $18.1 \%$ among students in Port-Said University, with statistically significant at $p \leq .05$.
Table 6 depicts that there is a statistically significant relation between hypertension and age, sex, BMI, nutrition, smoking, exercise, stress and family history among university students.

ISSN 1925-4040 E-ISSN 1925-4059 
Table 4. Distribution of the study sample groups according to physical measurements

\begin{tabular}{|c|c|c|c|c|c|c|c|c|c|c|}
\hline & \multicolumn{4}{|c|}{ Damietta $(n=1,134)$} & \multirow{3}{*}{$p$} & \multicolumn{4}{|c|}{ Port-Said $(n=895)$} & \multirow{3}{*}{$p$} \\
\hline & \multicolumn{2}{|c|}{ Male $(n=394)$} & \multicolumn{2}{|c|}{ Female $(n=740)$} & & \multicolumn{2}{|c|}{ Male (n = 339) } & \multicolumn{2}{|c|}{ Female $(n=556)$} & \\
\hline & No. & $\%$ & No. & $\%$ & & No. & $\%$ & No. & $\%$ & \\
\hline \multicolumn{11}{|l|}{ Systolic BP } \\
\hline Normal & 184 & 46.7 & 510 & 68.9 & \multirow{4}{*}{$\begin{array}{l}\chi^{2}(p) \\
<.001^{*}\end{array}$} & 153 & 45.1 & 378 & 68.0 & \multirow{4}{*}{$\begin{array}{l}\chi^{2}(p) \\
<.001^{*}\end{array}$} \\
\hline Pre hypertension & 98 & 24.9 & 138 & 18.6 & & 109 & 32.2 & 140 & 25.2 & \\
\hline Stage I hypertension & 20 & 5.1 & 43 & 5.8 & & 28 & 8.3 & 23 & 4.1 & \\
\hline Stage II hypertension & 92 & 23.4 & 49 & 6.6 & & 49 & 14.5 & 15 & 2.7 & \\
\hline \multicolumn{11}{|l|}{ Diastolic BP } \\
\hline Normal & 205 & 52.0 & 440 & 59.5 & \multirow{4}{*}{$\begin{array}{l}\chi^{2}(p) \\
<.001^{*}\end{array}$} & 181 & 53.4 & 389 & 70.0 & \multirow{4}{*}{$\begin{array}{l}\chi^{2}(p) \\
<.001^{*}\end{array}$} \\
\hline Pre hypertension & 50 & 12.7 & 159 & 21.5 & & 76 & 22.4 & 109 & 19.6 & \\
\hline Stage I hypertension & 41 & 10.4 & 76 & 10.3 & & 39 & 11.5 & 38 & 6.8 & \\
\hline Stage II hypertension & 98 & 24.9 & 65 & 8.8 & & 43 & 12.7 & 20 & 3.6 & \\
\hline \multicolumn{11}{|l|}{ Weight (kg) } \\
\hline$<60$ & 33 & 8.4 & 175 & 23.6 & \multirow{3}{*}{$\begin{array}{l}\chi^{2}(p) \\
<.001^{*}\end{array}$} & 32 & 9.4 & 145 & 26.1 & \multirow{3}{*}{$\begin{array}{l}\chi^{2}(p) \\
<.001^{* *}\end{array}$} \\
\hline $60-79$ & 284 & 72.1 & 482 & 65.1 & & 209 & 61.7 & 378 & 68.0 & \\
\hline$\geq 80$ & 77 & 19.5 & 83 & 11.2 & & 98 & 28.9 & 33 & 5.9 & \\
\hline Mean \pm SD & \multicolumn{2}{|c|}{$71.05 \pm 11.77$} & \multicolumn{2}{|c|}{$66.92 \pm 10.89$} & $\begin{array}{l}t(p) \\
<.001^{*}\end{array}$ & \multicolumn{2}{|c|}{$75.11 \pm 16.80$} & \multicolumn{2}{|c|}{$65.60 \pm 9.46$} & $\begin{array}{l}t(p) \\
<.001^{*}\end{array}$ \\
\hline Height (cm) & \multicolumn{2}{|c|}{$166.5 \pm 8.05$} & \multicolumn{2}{|c|}{$159.5 \pm 11.61$} & $\begin{array}{l}t(p) \\
<.001^{*}\end{array}$ & \multicolumn{2}{|c|}{$170.9 \pm 10.12$} & \multicolumn{2}{|c|}{$159.9 \pm 13.57$} & $\begin{array}{l}t(p) \\
<.001^{*}\end{array}$ \\
\hline \multicolumn{11}{|l|}{ BMI } \\
\hline Underweight & 7 & 1.8 & 18 & 2.4 & \multirow{4}{*}{$\begin{array}{l}\chi^{2}(p) \\
=.033^{*}\end{array}$} & 6 & 1.8 & 14 & 2.5 & \multirow{4}{*}{$\begin{array}{l}\chi^{2}(p) \\
=.001^{*}\end{array}$} \\
\hline Normal & 198 & 50.3 & 305 & 41.2 & & 183 & 54.0 & 266 & 47.8 & \\
\hline Overweight & 129 & 32.7 & 290 & 39.2 & & 94 & 27.7 & 217 & 39.0 & \\
\hline Obese & 60 & 15.2 & 127 & 17.2 & & 56 & 16.5 & 59 & 10.6 & \\
\hline Mean \pm SD & \multicolumn{2}{|c|}{$25.98 \pm 8.89$} & \multicolumn{2}{|c|}{$27.13 \pm 12.13$} & $\begin{array}{l}t(p) \\
=.099\end{array}$ & \multicolumn{2}{|c|}{$26.59 \pm 20.56$} & 27.66 & & $\begin{array}{l}t(p) \\
=.466\end{array}$ \\
\hline
\end{tabular}

$\chi^{2}(p): p$ value for chi square test; *: Statistically significant at $p \leq .05 ; t(p): p$ value for student $t$-test.

Table 5. Prevalence of hypertension among the study sample groups

\begin{tabular}{|c|c|c|c|c|c|c|c|}
\hline & \multicolumn{3}{|c|}{ Damietta } & \multicolumn{3}{|c|}{ Port-Said } & \multirow{2}{*}{$p$} \\
\hline & Total & Hyper & $\%$ & Total & Hyper & $\%$ & \\
\hline Male & 394 & 144 & 36.5 & 339 & 98 & 28.9 & $.028^{*}$ \\
\hline Female & 740 & 157 & 21.2 & 556 & 64 & 11.5 & $<.001^{*}$ \\
\hline Total & 1,134 & 301 & 26.5 & 895 & 162 & 18.1 & $<.001^{*}$ \\
\hline
\end{tabular}

$\chi^{2}(p)$ : Value for chi square test; *: Statistically significant at $p \leq .05$.

Results of Multiple Logistic Regression analysis in Table 6 indicate that Family history are (OR $=1.638$; CI: 1.1492.335), age (OR $=1.545$, CI: $1.296-1.841)$ and BMI (OR $=1.468$, CI: 1.256- 1.715) are the best predictors of hypertension. Also sex (OR = 0.551, CI: 0.417-0.729), smoking $(\mathrm{OR}=0.495$, CI: 0.350-0.700) and some drinks as tea (OR $=1.450$, CI: $1.090-1.930$ ) has increased estimated risk of hypertension.

\section{Discussion}

Hypertension is prevalent worldwide and current evidence suggests further increases in the prevalence of hypertension Published by Sciedu Press among people. Hypertension leads to increasing morbidity and mortality Hypertension increased progressively in younger age groups among the past 20 years. ${ }^{[15]}$

The results of the present study reported that prevalence of hypertension was $26.5 \%$ among students in Damietta University compared to $18.1 \%$ among students in Port Said University. This result is in line with a study conducted on Iranian college students revealing that the prevalence of hypertension was $23.8 \%{ }^{[16]}$

The study results revealed that males had significantly higher blood pressure than females. These results were similar to 
Grotto et al. ${ }^{[17]}$ who found that males were affected more often than females (40\% versus $23 \%$ ) among young Israeli adults. In contrast studies conducted in Turkey and other countries have shown that females have a significantly higher prevalence than males. ${ }^{[18]}$ Furthermore, Jaddou et al. ${ }^{[19]}$ reported that. SBP and DBP were significantly higher in females than in males especially during the early and mid adolescent stages. This gender difference in blood pressure pattern may be attributed to hormonal changes that occur during puberty which have been noted to occur more rapidly in females than in males.

Table 6. Univariate analysis of risk factors associated with hypertension among university students

\begin{tabular}{|c|c|c|c|c|c|c|}
\hline & \multicolumn{2}{|c|}{ Normal } & \multicolumn{2}{|c|}{ Hypertension } & & \multirow{2}{*}{$p$} \\
\hline & No. & $\%$ & No. & $\%$ & & \\
\hline \multicolumn{7}{|l|}{ Age } \\
\hline $18-20$ & 430 & 27.5 & 50 & 10.8 & \multirow{4}{*}{$62.223^{*}$} & \multirow{4}{*}{$<.001^{*}$} \\
\hline $20-22$ & 908 & 58.0 & 316 & 68.3 & & \\
\hline $22-24$ & 199 & 12.7 & 92 & 19.9 & & \\
\hline$>24$ & 29 & 1.9 & 5 & 1.1 & & \\
\hline \multicolumn{7}{|l|}{ Sex } \\
\hline Male & 491 & 31.4 & 242 & 52.3 & \multirow{2}{*}{$67.736^{*}$} & \multirow{2}{*}{$<.001^{*}$} \\
\hline Female & 1,075 & 68.6 & 221 & 47.7 & & \\
\hline \multicolumn{7}{|l|}{ BMI } \\
\hline$<18.5$ under weight & 28 & 1.8 & 17 & 3.7 & \multirow{4}{*}{$78.864^{*}$} & \multirow{4}{*}{$<.001^{*}$} \\
\hline 18.5-24.9 normal weight & 798 & 51.0 & 154 & 33.3 & & \\
\hline 25.0-29.9 over weight & 558 & 35.6 & 172 & 37.1 & & \\
\hline$\geq 30$ obese & 182 & 11.6 & 120 & 25.9 & & \\
\hline \multicolumn{7}{|l|}{ Nutrition Carbohydrate } \\
\hline Much & 208 & 13.3 & 136 & 29.4 & \multirow{3}{*}{$67.652^{*}$} & \multirow{3}{*}{$<.001^{*}$} \\
\hline Moderate & 1,076 & 68.7 & 271 & 58.5 & & \\
\hline Few & 282 & 18.0 & 56 & 12.1 & & \\
\hline \multicolumn{7}{|l|}{ Salt } \\
\hline High & 1,030 & 65.8 & 262 & 56.6 & \multirow{3}{*}{$13.095^{*}$} & \multirow{3}{*}{$.001^{*}$} \\
\hline Moderate & 51 & 3.3 & 18 & 3.9 & & \\
\hline Low & 485 & 31.0 & 183 & 39.5 & & \\
\hline \multicolumn{7}{|l|}{ Drink } \\
\hline Coffee & 346 & 22.1 & 161 & 34.8 & $30.647^{*}$ & $<.001^{*}$ \\
\hline Tea & 1,064 & 67.9 & 306 & 66.4 & 0.560 & .454 \\
\hline Other & 383 & 24.5 & 80 & 17.3 & $10.456^{*}$ & $.001^{*}$ \\
\hline \multicolumn{7}{|l|}{ Smoking } \\
\hline Non smoker & 1,430 & 91.3 & 327 & 70.6 & \multirow{2}{*}{$131.764^{*}$} & \multirow{2}{*}{$<.001^{*}$} \\
\hline Smoker & 136 & 8.7 & 136 & 29.4 & & \\
\hline \multicolumn{7}{|l|}{ Physical activity } \\
\hline Yes & 488 & 31.2 & 90 & 19.4 & \multirow{3}{*}{$62.227^{*}$} & \multirow{3}{*}{$<.001^{*}$} \\
\hline No & 339 & 21.6 & 181 & 39.1 & & \\
\hline Sometimes & 739 & 47.2 & 192 & 41.5 & & \\
\hline Stress & & & & & & \\
\hline Always & 490 & 31.3 & 235 & 50.8 & & \\
\hline Sometimes & 951 & 60.7 & 212 & 45.8 & $62.346^{*}$ & $<.001^{*}$ \\
\hline Never & 125 & 8.0 & 16 & 3.5 & & \\
\hline Family history & & & & & & \\
\hline Yes & 895 & 57.1 & 356 & 76.9 & $59031^{*}$ & $<001^{*}$ \\
\hline No & 671 & 42.9 & 107 & 23.1 & 39.001 & -.001 \\
\hline
\end{tabular}

$\chi^{2}$ : Chi square test; $*$ : Statistically significant at $p \leq .05$. 
Table 7. Multivariate analysis logistic regression of risk factors associated with hypertension among university students

\begin{tabular}{llllll}
\hline & B & Sig. & \multirow{2}{*}{ OR } & 95\% CI \\
\cline { 5 - 6 } & & & LL & UL \\
\hline Age (years) & 0.435 & $<.001^{*}$ & 1.545 & 1.296 & 1.841 \\
Sex & -0.596 & $<.001^{*}$ & 0.551 & 0.417 & 0.729 \\
BMI & 0.384 & $<.001^{*}$ & 1.468 & 1.256 & 1.715 \\
Carbohydrate & 0.162 & .134 & 0.850 & 0.687 & 1.051 \\
Salt & -0.666 & .032 & 0.514 & 0.280 & 0.944 \\
Smoking & 0.703 & $<.001^{*}$ & 0.495 & 0.350 & 0.700 \\
Drink & & & & & \\
Coffee & -0.013 & .926 & 0.987 & 0.742 & 1.313 \\
Tea & 0.372 & $.011^{*}$ & 1.450 & 1.090 & 1.930 \\
Other & 0.494 & $.006^{*}$ & 1.640 & 1.156 & 2.326 \\
Physical activity & 0.104 & .151 & 1.110 & 0.963 & 1.279 \\
Stress & -0.525 & $<.001^{*}$ & 0.592 & 0.478 & 0.732 \\
Family history & 0.494 & $.006^{*}$ & 1.638 & 1.149 & 2.335 \\
Father & 0.147 & .329 & 1.158 & 0.862 & 1.555 \\
Mother & -0.658 & $<.001^{*}$ & 0.518 & 0.384 & 0.699 \\
\hline S & & & &
\end{tabular}

* Statistically significant at $p \leq .05$.

According to the present study results, a statistically significant relationship was revealed between low family income with elevated hypertension among university students, the findings were in contradiction with those of Al-Nozha et $a l .{ }^{[20]}$ who founded that hypertension was significantly more in the lowest-income group. As well as Kearney et al. and Soliman et al.$^{[5,21]}$ have emphasized that low socioeconomic status was associated with elevated rates of blood-pressure related cardiovascular disease.

The results of the present study showed that the prevalence of hypertension was higher in students at Damietta University than in students at Port-Said University. The current findings showed significant geographical variation in hypertension prevalence where the central region had the highest and the southern region had the lowest prevalence of hypertension. Geographical variations in the prevalence of hypertension were reported by many studies in different regions of the world. ${ }^{[22,23]}$ These regional variations in hypertension may also be related to variation in socioeconomic, demographic, dietary and geographic characteristics.

The present study revealed a statistically significant relationship between hypertension and age, sex, BMI, nutrition, smoking, exercise, stress, and family history. These findings are supported by Simão et al. ${ }^{[24]}$ who reported that risk factors for hypertensive disease, can be mentioned as age, gender, genetic (race and family history) and environmental factors, including excessive consumption of salt, alcohol, fat and smoking.

Published by Sciedu Press
In the present study, the family history was the factor most strongly associated with hypertension in the students. This result is congruent with Naim Nur et al. and Abd El-Mohsen et al. ${ }^{[25,26]}$ who emphasized that in Turkey, if one parent was hypertensive, the probability of their children being hypertensive may be $28 \%$. If both the parents are hypertensive, the probability of their children being hypertensive may be $41.0 \%$. This study strongly supports the fact that the increase in prevalence of adolescent hypertension is highly significant among parents with hypertension.

The present study revealed that a strong relationship between hypertension and dietary habits like excessive consumption of carbohydrates, salts, tea and coffee with statistically significant differences and the hypertensive status. These findings incongruent with Sundar et al. and Savitha et al. ${ }^{[13,27]}$ who reported that no statistically significant relationship between dietary habits and hypertension.

The present study indicated that BMI is highly associated with a higher prevalence of hypertension among university students. This result was agreed with Oladapo et al. ${ }^{[28]}$ who demonstrated a significant relationship between hypertension in university students with a BMI $\geq 25$. This result is in line with Pang et al. and Sarry El-Din et al. ${ }^{[1,29]}$ who had confirmed that obesity and being overweight were the major risk factors in hypertension.

The present study emphasized that students who smoked, had statistically significant relationship with hypertension. 
This finding was congruent with Sundar et al. and Ibrahim et al. ${ }^{[13,30]}$ who reported that increased risk of hypertension was directly associated with an increase of daily cigarette smoking. Furthermore, Abd El-Mohsen et al. ${ }^{[26]}$ reported that the smoking and hypertension were known to accelerate the development of the process of atherosclerosis and increase the risk of all other coronary lesions.

For risk factors like physical activity, the present study revealed a statistically significant relationship between physical activity and hypertension. These findings are supported by Arafa et al. ${ }^{[2]}$ who demonstrated statistically significant relationships between exercises and hypertension. Furthermore, Simão et al. and Hujova et al. ${ }^{[24,31]}$ revealed that increasing physical activity and changing eating habits may decrease future hypertension morbidity and mortality. Nonetheless, these results had disagreement with Sundar et al. ${ }^{[13]}$ who showed that physical activity, had no significant relationship with hypertension in students in India.

It was observed from the current results that, the prevalence of hypertension was more common among those students under stress. As well as, the results indicated a significant relationship between stress and hypertension. This is consistent with the findings of a study done in Fayoum which reported a direct relationship between stress and hypertension. ${ }^{[5]}$

\section{Conclusion}

The findings of the present study highlighted the prevalence of hypertension is $26.5 \%$ among students in Damietta University, and $18.1 \%$ among students in Port Said University. The blood pressure values increased with associated risk factors (age, sex, BMI, smoking stress, physical activity and family history).

\section{Recommendations}

The current results were recommended that a periodic screening and monitoring of blood pressure of students should be incorporated into the university entrance physical examination, and university students health education on hypertension as a disease and its associated risk factors should be strengthened.

\section{ACKNOWLEDGEMENTS}

Thanks to the participants who provided valuable information and time for this study. We also would like to extend our appreciation to University Students for their cooperation and assistance while conducting the study.

\section{CONFLICTS OF INTEREST Disclosure}

The authors report no conflicts of interest. The authors alone are responsible for the content and writing of the paper.

\section{REFERENCES}

[1] Sarry El-Din AM, Erfan M, Kandeel WA, et al. Prevalence of Prehypertension and Hypertension in a sample of Egyptian Adults and its Relation to Obesity. Australian Journal of Basic and Applied Sciences. 2012; 6(13): 481-489.

[2] Arafa VSA, Ez-Elarab HS. Epidemiology of Pre-hypertension and Hypertension among Egyptian Adults. The Egyptian Journal of Community Medicine. 2011; 29(1): 1-18.

[3] World Health Organization. Global Status Report on Non communicable Diseases 2010. Geneva: World Health Organization; 2011.

[4] Aounallah-Skhiri H, El Ati J, Traissac P, et al. Blood pressure and associated factors in a North African adolescent population. a national cross-sectional study in Tunisia. BMC Public Health. 2012. PMid:22305045 http://dx.doi.org/10.1186/1471-2 458-12-98

[5] Soliman M, El-Salamony O, El-KhashabK A, et al. Study of Hypertension among Fayoum University Students. International Journal of Public Health Research. 2014; 2(2): 15-19.

[6] Erem C, Hacihasanoglu A, Kocak M, et al. Prevalence of prehypertension and hypertension and associated risk factors among Turkish adults: Trabzon Hypertension Study. Journal of Public Health. 2009; 31(1): 47-58. PMid:18829520 http://dx.doi.org/10.1093/p ubmed/fdn078

[7] Ejike CE, Ugwu CE, Ezeanyika LU. Variations in the prevalence of point (pre) hypertension in a Nigerian school-going adolescent population living in a semi-urban and an urban area. BMC Pediatr.
2010; 10: 13-7. PMid:20214768 http://dx.doi.org/10.1186 /1471-2431-10-13

[8] Culhane-Pera KA, Moua M, DeFor TA, et al. Cardiovascular disease risks in Hmong refugees from Wat Tham Krabok, Thailand. J Immigr Minor Health. 2009; 11: 372-9. PMid:19101803 http: //dx.doi.org/10.1007/s10903-008-9211-x

[9] Ibhazehiebo K, Dimkpa UI, Iyawe VI. Hypertension and blood pressure response to graded exercise in young obese and non-athletic Nigerian university students. Niger J Physiol Sci. 2007; 22: 37-42. PMid: 18379616

[10] Moore WE, Eichner JE, Cohn EM, et al. Blood pressure screening of school children in a multiracial school district: The Healthy Kids Project. Am J Hypertens. 2009; 22: 351-6. PMid:19214168 http://dx.doi.org/10.1038/ajh.2009.13

[11] Kemppainen V, TossavainenK, Turunen H. Nurses roles in health promotion practice: an integrative review, Department of Nursing science, Faculty of health sciences, University of Eastern Finland, Canthia-Building, Finland. 2012

[12] Disease and conditions Index-Hypotension. National Heart Lung and Blood Institute. 2008. Available from: http://www.nhlbi.nih. gov/health/dci/Diseases/hyp/hyp_whatis.html

[13] Sundar JS, Adaikalam JMS, Parameswari S, et al. Prevalence and Determinants of Hypertension among Urban School Children in the Age Group of 13-17 Years in, Chennai, Tamilnadu. Epidemiol. 2013; 3: 130. http://dx.doi.org/10.4172/2161-1165.1000130

[14] Obesity: Preventing and managing the global epidemic: Report of a World Health Organization Consultation. Geneva, Switzerland: Pre- 
sented at the World Health Organization; 1997. Jun, World Health Organization.

[15] Egypt Demographic and Health Survey (EDHS), 2008.

[16] Alikhani S, Delayari A, Alaedini F, et al. A province-based surveillance system for the risk factors of non-communicable diseases: A prototype for integration of risk factor surveillance into primary health care systems of developing countries. Public Health. 2009; 123: 358-64. PMid:19386334 http://dx.doi.org/10.1016/j .puhe.2009.02.011

[17] Grotto I, Huerta M, Sharabi Y. Hypertension and socioeconomic status. Current Opinion in Cardiology. 2008; 23(4): 335339. PMid:18520717 http://dx.doi.org/10.1097/HCO.0b013 e3283021c70

[18] Arslantas D, Ayranci U, Unsal A, et al. Prevalence of hypertension among individuals aged 50 years and over and its impact on health related quality of life in a semi-rural area of western Turkey Chinese Medical Journal. 2008; 121(16): 1524-1531.

[19] Jaddou HY, Bateiha AM, Khawaldeh AM, et al. Blood pressure profile in school children and adolescents in Jordan. Ann Saudi Med. 2001; 21: 123-126. PMid:17264612

[20] Al-Nozha M, Abdullah M, Arafah MR, et al. Hypertension in Saudi Arabia. Saudi Medical Journal. 2007; 28(1): 77-84. PMid:17206295

[21] Kearney PM, Whelton M, Reynolds K, et al. Global burden of hypertension: analysis of worldwide data. The Lancet. 2005; 365(9455): 217-223. http://dx.doi.org/10.1016/S0140-6736(05)701 $51-3$

[22] Saeed N, Al-Hamdan A, Kutbi A, et al. Characteristics risk factors and treatment practices of known adult hypertensive patients in Saudi Arabia. International Journal of Hypertension. 2010.
[23] Abed Y, Abu-Haddaf S. Risk Factors of Hypertension at UNRWA Primary Health Care Centers in Gaza Governorates. ISRN Epidemiology. 2013.

[24] Simão M, Hayashida M, Santos CB, et al. Hypertension among undergraduate students from Lubango, Angola. Rev Latino-am Enfermagem, julho-agosto. 2008; 16(4): 672-8. http://dx.doi.org /10.1590/S0104-11692008000400004

[25] NaimNur N, Çetinkaya S, YilmazA, et al. Prevalence of Hypertension among High School Students in a Middle Anatolian Province of Turkey. Health PopulNutr. 2008; 26(1): 88-94. Available from: http://www.ncbi.nlm.nih.gov/pubmed/18637532

[26] Abd El-Mohsen AS, Abd El Maksoud MM, Shokier TT. Prevalence of Hypertension among Youth in Helwan University. Life Sci J. 2013; 10(3): 2304-2308.

[27] Savitha MR, Krishnamurthy B, Fatthepur SS, et al. Essential hypertension in early and mid-adolescence. Indian J Pediatr. 2007; 74: 1007-1011. http://dx.doi.org/10.1007/s12098-007-0 185-9

[28] Oladapo OO, Salako L, Sodig O, et al. A prevalence of cardiometabolic risk factorsamong a rural Yoruba south-western Nigerian population: Apopulation-based survey. Cardiovasc J Afr. 2010; 21: 26-31. PMid:20224842

[29] Pang W, Li Z, Sun Z, et al. Prevalence of hypertension and associated factors among older rural adults: results from Liaoning Province, China. Med Princ Pract. 2010; 19(1): 22- 27. http: //dx.doi.org/10.1159/000252830

[30] Bani IA. Prevalence and related risk factors of Essential Hypertension In Jazan region, Saudi Arabia. Sudanese Journal of Public Health. 2011; 6(2): 54-50.

[31] Hujova $Z$. The prevalence of obesity and hypertension among firstyear students at Trnava University in Slovakia. International Journal of Medicine and Medical Sciences. 2013; 5(8): 361-367. 